\title{
KELSEN Y LA ÉTICA \\ UNIVERSALISTA ${ }^{1}$
}

Agustín E. Ferraro

Universidad de Buenos Aires (Argentina)

\begin{abstract}
- elsen sostuvo en numerosas ocasiones que su Teoría Pura del Derecho debía entenderse como una teoría valorativamente neutral. También es conocido su escepticismo en materia ética. Sin embargo, voy a intentar mostrar en este trabajo que Kelsen desarrolla su concepción de la norma fundamental utilizando una ética universalista como base metodológica y que, de esta forma, la Teoría Pura del Derecho contiene presuposiciones valorativas.
\end{abstract}

\section{La relación entre Cohen y Kelsen}

La ética universalista que, en mi opinión, más se aproxima a la que Kelsen utiliza para desarrollar su concepción de la norma fundamental, es la formulada por Hermann Cohen, fundador de la escuela neokantiana de Marburgo. Ciertas similitudes entre la teoría jurídica de Kelsen y la ética de Cohen fueron señaladas ya en la reseña que del primer libro de Kelsen se publicó en la influyente revista Kantstudien. ${ }^{2}$ Hay que notar que, a la fecha, Kelsen desconocía por completo la obra de Cohen. Dicha reseña, curiosamente, lo llevó a estudiar en particular la teoría ética que Cohen todavía estaba formulando en aquellos años. ${ }^{3}$ Tiempo después reconocía Kelsen a la obra de Cohen como una de las principales fuentes de inspiración de su Teoría Pura del Derecho. ${ }^{4}$ La conexión teórica entre Cohen y Kelsen se convirtió a partir de entonces en un tópico universalmente aceptado. En lengua castellana se mantuvo una gran atención a este trasfondo filosófico de la

${ }^{1}$ Agradezco los comentarios realizados a versiones anteriores de este trabajo por Osvaldo Guariglia, Klaus Günther, Ernesto Garzón Valdés y Stanley Paulson.

${ }^{2}$ Ewald, Oscar, «Die deutsche Philosophie im Jahre 1911», Kantstudien, vol. XVII, 1912, pp. 382-433, p. 398.

${ }^{3}$ Cfr. Kelsen, Hans, Hauptprobleme der Staatsrechtslehre. Entwickelt aus der Lehre vom Rechtssatze, $2^{\circ}$ reimpresión de la $2^{\circ}$ edición (Tübingen 1923), Aalen, Scientia, 1984, p. XVII.

${ }^{4}$ Ibid. 
obra de Kelsen, temática que no estuvo ausente de las obras de pensadores, por mencionar sólo algunos, como Luis Legaz y Lacambra, Luis Recasens Siches, Carlos Cossio o Roberto Vernengo, según expone recientemente Dante Cracogna en su tesis doctoral para la Facultad de Derecho de la Universidad de Buenos Aires. ${ }^{5}$ La iusfilosofía en lengua castellana continuó así una tradición interpretativa de Hans Kelsen que, paradójicamente, resultó interrumpida durante varias décadas en lengua alemana, desde que, como señala Winter, «la censura y cesura de los años '30 convirtieron a Cohen, después de la segunda guerra mundial, en un autor olvidado.» ${ }^{6}$ Todavía en 1980 podía señalar Winter la dificultad material de acceder a las obras de Cohen, que habían desaparecido de las bibliotecas alemanas en 1933. ${ }^{7}$ Poco tiempo antes, sin embargo había ya comenzado la muy necesaria edición de las obras completas de Cohen, bajo la dirección de Helmut Holzhey, ${ }^{8}$ quien a la vez reiniciaba la discusión en lengua alemana sobre la relación teórica entre Cohen y Kelsen. ${ }^{9}$

Ahora bien, en la nueva discusión en lengua alemana, la tesis que se consideró establecida desde 1911 ha sido seriamente criticada. Pues por lo menos dos de las más importantes monografías aparecidas en estos años sobre la filosofía jurídica del neokantismo ponen en duda que la tan mentada influencia de Cohen sobre Kelsen haya sido más que meramente superficial. En ambos casos se apunta a un problema evidente: ¿cómo puede considerarse que Cohen haya influido a Kelsen, cuando la teoría jurídica de éste se pretende libre de valores, lo que contradice de plano toda posible intención que aquél pudiera haber tenido al desarrollar una ética?

Así por ejemplo, para Winter, «la pregunta es, sin embargo, si resulta posible desmembrar a la ética de Cohen, de forma que -a pesar de haber sido esta ética plenamente desarrollada, como "doctrina de los principios de la filosofía del derecho y del Estado", en la tradición iusnaturalista e ilustrada que Kant perfeccionó- los momentos substantivos aparezcan mera-

${ }^{5}$ Cracogna, Dante, La fundamentación normativa del derecho en Kelsen. Crisis y crítica, Tesis doctoral, Facultad de Derecho y Ciencias Sociales, Universidad de Buenos Aires, 1995. Agradezco a Roberto Vernengo el haberme señalado la importancia de esta tradición iusfilosófica en lengua castellana.

${ }^{6}$ Winter, Eggert, Ethik und Rechtswissenschaft. Eine historisch-systematische Untersuchung zur Ethik-Konzeption des Marburger Neukantianismus im Werke Hermann Cohens, Berlin, Dunker \& Humboldt, 1980, p. 39.

${ }^{7}$ Ibid.

${ }^{8}$ Cohen, Hermann, Werke, 16 tomos, edición del Archivo Hermann Cohen en el Seminario Filosófico de la Universidad de Zürich, bajo la dirección de Helmut Holzhey, Hildesheim, Georg Olms, 1977 y ss.

9 Holzhey, Helmut, «Die Transformation neukantianischer Theoreme in die Reine Rechtslehre Kelsens», Archiv für Rechts- und Sozialphilosophie, Beiheft 20, 1984, pp. 96-110. 
mente como residuos impuros, debidos a una mirada metódica aún no desarrollada por completo, y una versión metódicamente refinada aparezca por primera vez en la figura de la Teoría Pura del Derecho de Kelsen con toda claridad y consecuencia.» ${ }^{10}$ En el mismo sentido, considera Müller que no puede aceptarse la tesis de que la ética de Cohen tienda hacia una teoría normativista como la de Kelsen, «[...] puesto que no puede corresponderle a la norma fundamental de Kelsen, en oposición al ideal de Estado de Cohen, una función de fundamentación ética, en tanto aquélla se encuentra arraigada en el nivel de la razón teórica.»» ${ }^{11}$

En mi opinión, el planteo de estas objeciones es correcto. Si los principios materiales de la ética de Cohen no pueden asociarse de ninguna manera con la Teoría Pura del Derecho, entonces la tesis de una conexión teórica entre Cohen y Kelsen se vuelve muy difícil de sostener. Pero creo apresurado negar a la Teoría Pura del Derecho toda asociación con el aspecto substancial de la ética de Cohen. En esto se encuentra, precisamente, el interés que me parece tener una investigación sobre la relación entre Cohen y Kelsen: el poder ganar un punto de vista que permita interpretar a la Teoría Pura del Derecho de forma que vuelva explícitos sus presupuestos valorativos. Estos presupuestos valorativos son, a mi juicio, propios de una ética universalista, y cumplen en la Teoría Pura del Derecho un papel metodológico sin perder por esto su carácter substancial.

El intento de explicitar presupuestos valorativos de la Teoría Pura del Derecho puede considerarse independiente del punto de vista histórico de una posible influencia de Cohen sobre Kelsen. Se trataría más bien de asumir un punto de vista reconstructivo, es decir, de interpretar la Teoría Pura del Derecho desde la perspectiva abierta por la ética de Cohen. La diferenciación entre dichos puntos de vista ha sido aplicada al problema por Stanley Paulson. ${ }^{12}$ Paulson ha intentado salvar con esta diferenciación dicha posibilidad de una interpretación de la obra de Kelsen a partir de la ética de Cohen. Pues la primera alternativa, esto es, el establecer una conexión histórica verdaderamente relevante entre ambos autores, ha sido puesta en duda por Paulson luego de un análisis textual detallado y exhaustivo de las referencias históricas presentes en los propios textos de Kelsen. Las conclu-

${ }^{10}$ Winter, E., Ethik und Rechtswissenschaft, op. cit., p. 35.

${ }^{11}$ Müller, Claudius, Die Rechtsphilosohpie des Marburger Neukantianismus. Naturrecht und Rechtspositivismus in der Auseinandersetzung zwischen Hermann Cohen, Rudolf Stammler und Paul Natorp, Tübingen, Mohr, 1994, p. 132 n. 139.

${ }^{12}$ Cfr. Paulson, Stanley, «Kelsen and the Marburg School: Reconstructive and Historical Perspectives», en: Krawietz, W./MacCormik, N./ von Wright, G. H. (eds.) Prescriptive Formality and Normative Rationality in Modem Legal Systems, Berlin, Duncker \& Humblot, 1994, pp. 481-494. 
siones de Paulson me parecen completamente sólidas: las referencias de Kelsen a su presunta deuda hacia Cohen son incluso exageradas, ${ }^{13}$ y ni siquiera puede sostenerse con seguridad que Kelsen tuviera un conocimiento tal de la obra de Cohen que le permitiese utilizarla como herramienta conceptual. ${ }^{14}$

A continuación entonces, siguiendo la propuesta de Paulson, ${ }^{15}$ voy a intentar formular un «tipo ideal» o teoría que refleje ciertas ideas básicas de la ética de Cohen en la forma más rigurosa y desarrollada posible, para hacer luego lo propio con el desarrollo de la concepción de la norma fundamental de Kelsen en dos de sus obras: la primera edición de la «Teoría Pura» de $1934^{16}$ y su obra anterior «El problema de la soberanía y la teoría del derecho internacional» de $1928,{ }^{17}$ que es, en cierto sentido, preparatoria de la primera respecto a la cuestión que voy a tratar en el presente trabajo. El resultado serán entonces dos «tipos ideales» uno coheniano y el otro kelseniano. A pesar de la dificultad de sostener una posible influencia histórica real entre ambos autores, creo que el «tipo ideal-Cohen» puede resultar sumamente explicativo para descubrir el uso de una ética universalista como método de la teoría jurídica en el «tipo ideal-Kelsen».

A los fines de este trabajo voy a conceder especial atención a la idea de Cohen de que la ética ha de tener con la ciencia jurídica una relación análoga a la relación de la lógica con la matemática. De aquí resulta su famosa tesis de que la ética es la lógica de la ciencia del derecho. Voy a exponer brevemente ahora cómo pone Cohen en práctica este principio metodológico, para pasar a mostrar luego su papel en el desarrollo de la concepción de la norma fundamental por parte de Hans Kelsen.

\section{El método de Cohen}

Cuando Cohen sostiene que la ética ha de cumplir el papel de una lógica de la ciencia jurídica entiende la lógica, particularmente, como lógica trascendental. Se trata entonces de mostrar que ciertos conceptos de la ética son la condición de posibilidad de conceptos de la ciencia jurídica, y, por tanto, condición de posibilidad de la realidad jurídica. Pues la noción de condición es fundamental en la idea del método trascendental de Cohen,

\footnotetext{
${ }^{13}$ Paulson, S., «Kelsen and the Marburg School», op. cit., p. 488s.

${ }^{14}$ Paulson, S., «Kelsen and the Marburg School», op. cit., p. 491.

${ }^{15}$ Paulson, S., «Kelsen and the Marburg School», op. cit., p. 484.

${ }^{16}$ Kelsen, Hans, Reine Rechtslehre. Einleitung in die rechtswissenschaftliche Problematik, $2^{\circ}$ reimpresión de la $1^{\circ}$ edición (Leipzig y Viena 1934), Aalen, Scientia, 1994.
}

${ }^{17}$ Kelsen, Hans, Das Problem der Souveranität und die Theorie des Völkerrechts. Beitrag zu einer Reinen Rechtslehre, $2^{\circ}$ reimpresión de la $2^{\circ}$ edición (Tübingen 1928), Aalen, Scientia, 1981. 
quien considera como expresión definitiva de la idea de trascendentalidad a la fórmula kantiana, de acuerdo con la cual, «las condiciones de posibilidad de la experiencia en general son, a la vez, condiciones de posibilidad del objeto de la experiencia». ${ }^{18}$ Vale la pena aclarar que el método trascendental de Cohen de ninguna manera es el método trascendental tal como originariamente lo enunciara Kant, según se verá más adelante. Sin embargo, la idea de que la lógica trascendental contiene las «condiciones» del conocimiento y, a la vez, del objeto, es uno de los elementos que Cohen conserva en su reelaboración del pensamiento kantiano. En este sentido ha señalado Geert Edel que «[...] Cohen permanece, por otro lado, por completo en la línea de la filosofía trascendental de Kant, dado que intenta reconducir el conocimiento problematizado (en Kant: juicios) a las condiciones o principios de su posibilidad, las que permiten, o están en condiciones de fundamentar su validez (en Kant: carácter a priori y referencia al objeto).» ${ }^{19}$

La forma en que tales condiciones o principios de posibilidad del conocimiento han de descubrirse no resulta sin embargo, en mi opinión, completamente explicitada por Cohen. Creo, sin embargo, que la estructura general que habría de tener este tipo de argumento puede elaborarse a partir de la fundamentación que expone Cohen de la universalidad del sujeto moral. Pero antes de pasar a este ejemplo particular del método trascendental de Cohen en la Ética voy a examinar brevemente sus declaraciones generales sobre la relación entre ética y ciencia del derecho en la obra más importante que dedicó a la cuestión, su Ética de la voluntad pura. ${ }^{20}$

Resulta claro para Cohen, en primer lugar, que de las ideas éticas se ha hecho muchas veces un uso hipócrita. Ahora bien, por más que las ideas éticas se presenten de forma velada y defectuosa en las relaciones de poder, el punto es para Cohen que las ideas éticas logren a pesar de todo presentarse «sich selbst zur Erscheinung bringen», ${ }^{21}$ y esto es lo que hace necesario concederles un rol metodológico.

$\mathrm{Al}$ relacionar Cohen esta idea con su crítica a Kant, expone la relación entre ambas disciplinas -ética y ciencia del derecho- como una relación de deducción: «[a]quí debe solamente subrayarse, que Kant abandonó en este punto la aplicación del método trascendental; que no lleva a cabo la deducción de la ética a partir de la ciencia jurídica como lo hizo con la lógica a

${ }^{18}$ Cfr. Cohen, Hermann, Kants Theorie der Erfahrung, reimp. de la $3^{\circ}$ edición, de 1918 en: Werke, Tomo 1, Parte 1.1, Helmut Holzhey (ed.), Hildesheim, Georg Olms, 1987, p. 190.

19 Edel, Geert, Von der Vernunftkritik zur Erkenntnislogik. Die Entwicklung der theorethischen Philosophie Hermann Cohens, Freiburg/München, Karl Alber, 1988, p. 123.

${ }^{20}$ Cohen, Hermann, Ethik des reinen Willens, reimp. de la $2^{\circ}$ edición de 1907, en Werke, Tomo 7, Parte 2, Helmut Holzhey (ed.), Hildesheim, Georg Olms, 1981.

${ }^{21}$ Cfr. Cohen, H., Ethik des reinen Willens, op. cit., pp. 36s. 
partir de la ciencia natural. ${ }^{22}$ La deducción a la que se refiere en este punto Cohen, que no cabe sino entender como deducción trascendental, de la ética a partir de la ciencia del derecho, no puede entenderse, sin embargo, en el sentido kantiano. Pues Cohen adopta respecto a la deducción trascendental una posición distinta a la de Kant y crítica de éste. Como señala Edel: «La "deducción trascendental" de Kant tiene para Cohen sólo un significado psicológico $\mathrm{y}$, en el mejor de los casos, metafísico, pero no tiene un rango trascendental. ${ }^{23}$ Para Cohen, la deducción que hace Kant de las categorías no es sino una mera teoría psicológica del aparato subjetivo del conocimiento. Cohen reformula esa deducción en un principio que ya no representa, como en Kant, la unidad de una consciencia personal o supra-empírico trascendental, sino que, exclusivamente, ha de representar la unidad de los principios del conocimiento y, con esto, la unidad de la experiencia científica. ${ }^{24}$ Edel ha formulado lo que Cohen entiende por una deducción trascendental de la siguiente manera: "Una deducción trascendental en el sentido de Cohen es única y exclusivamente la demostración de las categorías [...] como los "fundamentos" o "unidades de pensamiento" de los principios [del conocimiento] [...]». ${ }^{25}$

Para Cohen, resulta entonces que la crítica del conocimiento se propone como objeto a «las ciencias en la consistencia de sus conceptos fundamentales y presuposiciones. En la medida en que descubrimos y ordenamos éstos, certificamos la validez de las condiciones a priori y hacemos filosofía crítica de acuerdo al método trascendental.» ${ }^{26}$

Cohen se propone extender esta idea del método trascendental a la filosofía práctica. Kant, sostiene Cohen, debería haber llevado a cabo una crítica de la razón pura práctica. Y con esto se le hubiera planteado a Kant el problema de ejercer la crítica de la ciencia jurídica de tal modo de indagar si en la ciencia jurídica la razón pura práctica, que Cohen denomina «voluntad pura», «llega a su cumplimiento» (in Vollzug trete), o también si «se deja certificar» ${ }^{27}$ (sich beglaubigen lasse).

El objetivo de este procedimiento es que los conceptos fundamentales de la Ética se muestren como los conceptos «generadores» (erzeugenden) de la ciencia jurídica. ${ }^{28}$

\footnotetext{
${ }^{22}$ Cohen, H., Ethik des reinen Willens, op. cit., p. 227.

${ }^{23}$ Edel, G., Von der Vernunftkritik zur Erkenntnislogik, op. cit., p. 416.

${ }^{24}$ Cfr. Edel, G., Von der Vernunftkritik zur Erkenntnislogik, op. cit., p. 458.

${ }^{25}$ Edel, G., Von der Vernunftkritik Zur Erkenntnislogik, op. cit., p. 416.

${ }^{26}$ Cohen, H., Kants Theorie der Erfahrung, op. cit., p. 740.

${ }^{27}$ Cohen, H., Ethik des reinen Willens, op. cit., p. 228.

${ }^{28}$ Cohen, H., Ethik des reinen Willens, op. cit., p. 229.
} 
Finalmente, al iniciar la exposición del principal concepto de la ética que debe ser puesto en correlación con la ciencia jurídica, es decir, el concepto de sujeto, señala Cohen que, de lo que se trata, es de «probar» (prüfen) y de «certificar» (beglaubigen) el sujeto de la ética a través del concepto de la persona jurídica. ${ }^{29}$

Ahora bien, ¿cómo es que se logra «mostrar» que un concepto de la ética es condición de posibilidad de un concepto de la ciencia jurídica, de forma de «certificar»o «probar» a aquél? Como señalaba antes, no me parece que Cohen sea completamente explícito en el punto, pero creo que puede llegarse en esto a cierta claridad si se lo pone en relación con el principio de la trascendentalidad mencionado más arriba, en cuanto que las condiciones de posibilidad de la experiencia son condiciones de posibilidad del objeto de la experiencia. Cuando se muestra que un concepto de la ética es condición de posibilidad de un concepto correspondiente de la ciencia jurídica, se muestra entonces también que ese concepto de la ética es condición de posibilidad de la realidad jurídica. Y es este último camino que la deducción que voy a presentar como ejemplo parece tomar: Cohen intenta mostrar que la personalidad jurídica, en cuanto real, presupone un sujeto moral universal. Voy a analizar a continuación dicha deducción.

\section{El sujeto de la ética}

El problema fundamental de la ética es, para Cohen, la determinación de su sujeto, problema que se manifiesta en la relación del individuo con la universalidad.

$\mathrm{Si}$ el individuo empírico es el único sujeto posible, la ética corre el riesgo de convertirse en una forma de la psicología. ${ }^{30}$ Pero si, por el contrario, se postula como sujeto a entidades universales de carácter metafísico, tales como el espíritu, la vida, etc., la ética amenazaría transformarse ya sea en metafísica dogmática o bien en religión.

La correlación del individuo con la universalidad sólo puede solucionarse propiamente, para Cohen, al desarrollar una concepción de la intersubjetividad en forma a priori. La idea de la intersubjetividad a priori es muy simple: el otro debe ser pensado en forma originaria con el yo.

El sujeto de la ética no puede por tanto ser el individuo. Al individuo puede pensárselo en forma independiente y separada de un otro. El otro es en ese caso mero producto de la experiencia: el individuo percibe su entorno, en el que encuentra otros hombres. Esto es propio del sujeto del conocimiento, y sería un error trasladarlo a la ética. Cohen opina que este error

\footnotetext{
${ }^{29} \mathrm{Ibid}$.

${ }^{30}$ Cohen, H., Ethik des reinen Willens, op. cit., p. 2s.
} 
fue cometido por Fichte, quien postula en el plano ético al yo como la autoconsciencia, a la que se enfrenta el no-yo. El no-yo es en Fichte la cosa, el objeto en general, todo objeto ${ }^{31}$. Pero no puede construirse una ética partiendo del yo monológico del sujeto de conocimiento, que es característico del idealismo, pues el otro resulta entonces un mero derivado.

Para Cohen, la ética tiene que colocar al otro en una posición mucho más fundamental y tan originaria como la del yo. El yo y el otro tienen que encontrarse para esto en una relación de correlación e incluso de continuidad. Pero no se trata de que el yo abarque al otro o viceversa, de que formen una entidad de mayor extensión, etc. Ambos deben permanecer aislados, pero presuponerse recíprocamente. El otro como presupuesto del yo y viceversa, es la tesis fundamental que Cohen intentará demostrar. De acuerdo con su concepto del método trascendental en la ética, se trata de mostrar a esta idea como condición de posibilidad de un concepto de la ciencia jurídica, en lo cual se muestra también que el concepto de la ética es condición de posibilidad de una realidad jurídica. Es decir, el concepto del yo como correlativo al otro ha de poder mostrarse como condición de posibilidad del factum del derecho, con lo cual el concepto de la ética es deducido trascendentalmente.

El punto de partida de Cohen es la persona jurídica. A través del contrato se funda en el derecho la abstracción de una persona jurídica. Ahora bien, no es posible el contrato sin presuponer un otro contratante. Es decir, en la relación contractual por la que se funda una persona jurídica nos encontramos con una presuposición del otro como la que buscamos para la persona ética. Lo interesante es que, para la jurisprudencia, nunca fue un problema considerar a ambos contratantes como conformando una unidad jurídicamente positiva, es decir, real, sin que ninguna de las partes contratantes pierda su individualidad. Se trata más bien de que los contratantes están referidos uno al otro de manera conceptual, de forma análoga a la relación conceptual entre personas gramaticales: «El contrato es una pretensión; una pretensión del derecho que yo planteo al otro. Una tal pretensión, por lo menos como pretensión judicial, es desde luego la acción jurídica en general (actio). Ahora bien, el contrato hace de la pretensión (Anspruch) una alocución (Ansprache). Y de aquí se transforma al otro en yo y tú [...] El yo y el tú se corresponden. No puedo decir tú, sin referirte a mí; sin enlazarte con el yo a través de esta referencia [...] Éste es el progreso del otro hacia el tú. Y este progreso es confirmado por la ficción jurídica. Así se acredita la persona jurídica como persona moral.» ${ }^{32}$

\footnotetext{
${ }^{31}$ Cohen, H., Ethik des reinen Willens, op. cit., p. 208.

${ }^{32}$ Cohen, H., Ethik des reinen Willens, op. cit., 247s.
} 
Resulta de esto que la persona jurídica, en cuanto unidad real de una pluralidad de individuos, manifiesta como factum la extensión intersubjetiva del sujeto de la ética, cuya posibilidad estaba en cuestión.

Cohen intenta elaborar esta idea del sujeto hasta mostrar que la forma más universal de pensar un sujeto, esto es, la humanidad, resulta concretada en la idea de una comunidad jurídica internacional. Sin embargo, a mi modo de ver, la argumentación de Cohen presenta a partir de este punto algunas dificultades.

La máxima extensión en que se manifiesta la referencia intersubjetiva de los individuos es, en principio, el Estado de Derecho, pues éste se presenta como la persona jurídica más abarcadora. Sin embargo, el Estado tiene que considerarse para esto, parcialmente, como un ideal o una tarea del sujeto ético, pues, sostiene Cohen «el Estado empírico no es sino el Estado de los estamentos y de las clases dominantes; no es el Estado de derecho. El Estado del poder sólo puede convertirse en Estado de derecho en la medida en que crea el derecho, no en interés de los estamentos y de las clases, sino de acuerdo con la idea del Estado.» ${ }^{33}$

El concepto de Estado se vuelve así en parte un ideal, de acuerdo con el desarrollo de un socialismo ético al que aspira Cohen. Sin embargo, desde el punto de vista metódico, la incorporación de dichos elementos ideales hacen del concepto de Estado más bien un desideratum y no ya el factum desde donde pueda procederse a la deducción trascendental de un concepto de la ética. A mi modo de ver habría en esto una cierta dificultad para la argumentación trascendental de Cohen.

Por un lado, que el Estado empírico ya no sirva como punto de partida para la deducción trascendental de un concepto de la ética, no le impide a Cohen considerar que aún aquel Estado conserva ciertos elementos ideales, desde donde viene a ser reconocido como persona jurídica. Los elementos ideales son en este plano todavía formulados como condición de posibilidad del Estado real. Criticando la distinción entre derecho privado y derecho público, afirma Cohen: «Se trata en esto las más de las veces, y con metódica consecuencia, del poder, fundado en la propiedad privada, de las clases dominantes, las que parecen conformar al Estado, puesto que lo gobiernan. A pesar de todo el Estado no puede escaparse por completo de la tarea que se designa con la fórmula pacta servare. En los tratados preserva el Estado la fidelidad. Y esta fidelidad conforma, a pesar de todos los abusos del poder dominante, su fundamento y su derecho ético; su derecho a ser reconocido como persona jurídica $[\ldots] \gg . .^{34}$

\footnotetext{
${ }^{33}$ Cohen, H., Ethik des reinen Willens, op. cit., p. 615.

${ }^{34}$ Cohen, H., Ethik des reinen Willens, op. cit., p. 242.
} 
Por otro lado, Cohen anuncia en la Introducción a la Ética de la voluntad pura que la universalidad intersubjetiva del lazo jurídico ha de mostrarse como verdaderamente internacional, superando así el particularismo que puede objetarse a un Estado nacional. Sin embargo, más allá de algunas referencias aisladas, Cohen no vuelve a tratar sistemáticamente esta cuestión. Como veremos, Kelsen parece reiniciar esa argumentación exactamente donde la deja Cohen, para demostrar que el derecho no puede captarse objetivamente desde el punto de vista de un Estado particular, sino sólo en términos universalistas. Voy a citar el párrafo en donde Cohen plantea el problema, para que pueda luego verse la medida en que puede interpretarse a Kelsen como si siguiese este programa. Dice Cohen: «Se mostrará que la oposición entre Estado y humanidad es sólo aparente. En la medida en que intentamos fundar la unidad del hombre en la unidad del Estado, no disociamos, por así decirlo, al hombre de la humanidad; sino que más bien nos apoderamos con esto de la herramienta apropiada para conducir a una verdadera superación a la oposición entre el hombre individual y la humanidad universal. Y la humanidad se vuelve sólo por este camino metódico una idea ética; mientras que, de lo contrario, no pasa de ser una piadosa creencia $[\ldots] . .{ }^{35}$

Para concluir esta breve exposición del método y de la ética de Cohen, voy a intentar formular dos ideas centrales que creo importantes para una reinterpretación de la Teoría Pura del Derecho.

1. El método trascendental deja de referirse a las facultades del sujeto, como en Kant, para mantenerse con exclusividad en el nivel de los presupuestos conceptuales.

2. La unidad del sujeto de la ética sólo puede pensarse a partir de una intersubjetividad a priori. La intersubjetividad a priori permite pensar la unidad de una multiplicidad de individuos bajo la forma de la universalidad. Es decir, en el nivel substantivo, la ética de Cohen parecería apoyarse en los conceptos de unidad y universalidad, cuya relación está dada en una forma a priori de la intersubjetividad. La persona jurídica, ya sea como Estado o como comunidad jurídica internacional, presupone dicha universalidad.

\section{El concepto ético del derecho en Kelsen}

Para Kelsen, la unidad del derecho en cuanto objeto del conocimiento es algo dado. Para poder explicar esta unidad previamente dada postula Kelsen su famosa norma fundamental (Grundnorm) lógico-transcendental, que representa la condición de posibilidad de esa unidad. Stanley Paulson ha caracterizado muy justamente a la norma fundamental, en este sentido, como

\footnotetext{
${ }^{35}$ Cohen, H., Ethik des reinen Willens, op. cit., p. 82.
} 
una suerte de «abreviatura» de una argumentación transcendental. ${ }^{36}$ El derecho aparece, en principio, como una multiplicidad de normas, que, sin embargo, conforman un sistema o una unidad. La norma fundamental es una hipótesis trascendental que explica cómo tal unidad puede estar dada. Puede decirse, entonces, que las normas forman una unidad o un sistema «cuando su validez puede ser retrotraída hasta una única norma como fundamento último de esa validez. Esta norma fundamental constituye como fuente común la unidad en la multiplicidad de todas las normas que forman un orden». ${ }^{37}$

$\mathrm{Su}$ carácter constitutivo de la unidad del derecho es lo que hace a la norma fundamental una condición lógico transcendental tanto del derecho como del conocimiento jurídico. En cuanto al conocimiento jurídico es la norma fundamental una hipótesis de la ciencia jurídica, pero en cuanto al derecho es ella, a la vez, el fundamento último de la validez o modo de existencia específico de las normas jurídicas.

Si el método trascendental de Kelsen tiene entonces algún paralelo con el de Cohen, podríamos esperar que la norma fundamental muestre algún tipo de contenido ético, por ser una condición lógico-transcendental del derecho. Una categoría del derecho tiene que ser en Cohen, a la vez, un concepto de la ética.

Como intentaré mostrar a continuación, es éste efectivamente el caso. Pero a más de presentar un contenido ético, puede observarse que la norma fundamental es condición de la unidad del derecho en tanto se la interpreta en términos universalistas. La unidad del Estado (y del derecho) se vincula así, demostrativamente, con el concepto universalista de la humanidad, con lo que puede interpretarse este argumento de Kelsen como la continuación de un programa formulado por Cohen.

En un primer paso argumenta Kelsen que la norma fundamental no puede ser entendida solamente como una norma nacional, esto es, como norma fundamental de un sistema jurídico determinado.

La norma fundamental de un sistema jurídico se revela en el contexto del derecho internacional como una norma jurídica positiva: un principio jurídico del derecho internacional, el así llamado principio de efectividad, a través del cual un poder establecido, bajo ciertas condiciones, es declarado como orden jurídico por la comunidad jurídica internacional. ${ }^{38}$ Pero sólo puede reconocerse a la norma fundamental de un sistema jurídico como

${ }^{36}$ Paulson, Stanley, «Vorwort zunt Nachdruck» en: Kelsen, H., Reine Rechtslehre, op. cit., pp. III-VIII, V.

${ }^{37}$ Kelsen, H., Reine Rechtslehre, op. cit., p. 62.

${ }^{38}$ Cfr. Kelsen, H., Reine Rechtslehre, op.cit., pp. 71, 150. 
norma positiva del derecho internacional «cuando uno entiende al derecho internacional como un orden jurídico superior a los órdenes jurídicos de los Estados individuales, en una relación de delegación hacia éstos»; pero en este caso «no puede hablarse de una norma fundamental como fundamento de los órdenes jurídicos de los Estados individuales, sino ya sólo como base del derecho internacional.» ${ }^{39}$ Está claro que una concepción del derecho internacional como ésta es completamente incompatible con la idea de la soberanía de los Estados nacionales.

Consecuentemente con esto, desarrolla Kelsen una cuidadosa crítica de la idea de la soberanía, a la que no considera sino un «dogma». Su argumentación es, en síntesis, la siguiente: sería contradictorio declarar a las normas del derecho internacional y a las del orden jurídico de un Estado simultáneamente como válidas, cuando las mismas se contradicen. En base a la soberanía se afirma entonces por lo general que las normas del derecho internacional sólo son válidas para un Estado cuando éste las «reconoce». De esta forma se evita la contradicción señalada, pero surge otro problema; puesto que «también la existencia jurídica de los otros Estados se basa en el reconocimiento por parte del propio, tiene uno que representarse el orden jurídico de este último como extendido sobre los otros órdenes jurídicos estatales.» ${ }^{40}$ Tal consecuencia de la soberanía del Estado vuelve a las intenciones políticas de la idea, según Kelsen, unívocas: a través de su soberanía es representado el Estado como la comunidad jurídica absolutamente superior. El problema de esta construcción teórica es que la soberanía, ante tales consecuencias que se desprenden de ella, no puede sino pensarse como exclusiva del propio Estado. La soberanía «no puede sino ser la del propio Estado, que forma el punto de partida de toda la construcción. Pues la soberanía de un Estado, en este sentido suyo originario, es incompatible con la soberanía de otro Estado.» ${ }^{41}$

Esa primacía del orden jurídico del propio Estado, que resulta de la idea de la soberanía, sólo puede corresponder a una concepción subjetivista, en donde la existencia del otro depende de su reconocimiento por el sujeto que lo percibe. Contra esto defiende Kelsen la tesis de que el derecho internacional y los órdenes jurídicos de los Estados particulares tienen que ser percibidos objetivamente como un sistema unificado (einheitlich) de normas. ${ }^{42}$

Dado que principio y fin de la validez jurídica de un orden estatal son reglados por un principio del derecho internacional, esto es, por el citado

\footnotetext{
${ }^{39}$ Kelsen, H., Reine Rechtslehre, op. cit., p. 72.

${ }^{40}$ Kelsen, H., Reine Rechtslehre, op. cit., p. 140.

${ }^{41}$ Kelsen, H., Reine Rechtslehre, op. cit., p. 141.

${ }^{42}$ Cfr. Kelsen, H., Reine Rechtslehre, op. cit., p. 135.
} 
principio de efectividad, es el derecho internacional el que determina tanto el ámbito espacial como el ámbito temporal de validez de los órdenes jurídicos estatales. De esta forma es que pueden verse a los órdenes jurídicos estatales y al derecho internacional como un sistema unificado.

Con esto llegamos al punto decisivo. La relativización del Estado que hace la Teoría Pura del Derecho permite considerar a aquél como un «órgano del derecho internacional», y esta expresión «produce en un sentido enteramente positivo la unidad del sistema jurídico universal.» ${ }^{43}$ La más alta unidad dada al conocimiento, esto es, la unidad de todo el derecho, es, a la vez, «la unidad de una comunidad jurídica universal» ${ }^{44}$, aun cuando ésta no esté dada en forma organizativa, es decir como Estado mundial.

Cabe ahora preguntarse qué entiende aquí Kelsen por «universal». Como ya sostuve, es mi opinión que dicha universalidad tiene que entenderse como una universalidad en el sentido de Cohen, es decir, una universalidad de la ética. Voy a examinar ahora este punto.

Kelsen presenta su propia concepción como «objetivista-universalista» frente al «subjetivismo» del dogma de la soberanía. También en oposición al subjetivismo habla en otro lugar del «carácter universalista de la Teoría Pura del Derecho». ${ }^{45}$

De aquí pasa Kelsen a argumentar contra el subjetivismo en general, una de cuyas consecuencias es el dogma de la soberanía. El desarrollo de la argumentación muestra un claro paralelo con la fundamentación que hace Cohen de la integración entre unidad y universalidad a través de la correlación del «yo» y el «tú». Cabe destacar que Kelsen también está sosteniendo la tesis de que la unidad del derecho remite a una comunidad jurídica universal. Voy a citar in extenso el correspondiente párrafo de Kelsen: «El subjetivismo, que para comprender al mundo parte del propio yo, y para esto extiende ese yo al universo, sin poder alcanzar un mundo objetivo por encima del propio yo soberano, ese subjetivismo es incapaz de captar al otro sujeto, al no-yo que se presenta con la misma pretensión de soberanía, al «tú» que también quiere ser un yo, como una entidad de la misma clase que el propio yo. $\rangle^{46}$

Con esto puede notarse que el «objetivismo» de la Teoría Pura del Derecho se corresponde con una concepción a priori de la intersubjetividad. La decisión por un punto de vista objetivista es, en otras palabras, independiente de la experiencia pero constitutiva de la misma. Por esto es que el

\footnotetext{
${ }^{43}$ Kelsen, H., Reine Rechtslehre, op. cit., p. 152s.

${ }^{44}$ Kelsen, H., Reine Rechtslehre, op. cit., p. 134s.

${ }^{45}$ Kelsen, H., Reine Rechtslehre, op. cit., p. 59s.

${ }^{46}$ Kelsen, H., Reine Rechtslehre, op. cit., p. 142.
} 
subjetivismo del dogma de la soberanía representa también un punto de vista posible, desde el momento en que permanece coherente consigo mismo. Dado que en ambos casos se trata de presuposiciones metodológicas, el punto de vista subjetivista es, en principio, posible: «no puede negarse la posibilidad teórica de un punto de vista desde el cual sólo el orden del propio Estado, y lo que se puede se puede captar desde él, serán interpretados como derecho.» ${ }^{47}$

La intersubjetividad a priori consiste para Kelsen, en cambio, como premisa fundamental, en el captar al «tú» como una entidad de la misma jerarquía que el propio «yo». Desde este punto de vista se hace por primera vez posible, para el conocimiento, «la unidad del sistema jurídico universal». En estos términos podía Kelsen con toda razón considerar su objetivismo como un universalismo. El punto central del universalismo de Cohen es, como se vio antes, el reconocimiento de una intersubjetividad a priori, que se desarrolla a partir de la correlación entre el yo y el tú, y que encuentra en la unidad de la persona jurídica el factum que demuestra su posibilidad.

Por cierto, Kelsen no postula una relación de continuidad entre el «yo» y el «tú» como lo hace Cohen; pero la idea de la intersubjetividad a priori, partiendo de la relación entre ambos, así como la identificación de dicha intersubjetividad con un punto de vista universalista, reproducen claramente el esquema y los contenidos de la argumentación de Cohen sobre el asunto. Con esto resulta por lo menos dudoso si es que Kelsen desarrolló la concepción de la norma fundamental de acuerdo con la forma de neutralidad valorativa que suele atribuírsele.

Que esto no es así puede notarse con mayor precisión en un trabajo anterior de Kelsen, El problema de la soberanía y la teoría del derecho internacional. Contribución para una Teoría Pura del Derecho, ${ }^{48}$ en donde se encuentra la suma de los materiales y argumentos respecto a la soberanía y el derecho internacional que en obras posteriores reaparecerán pero muy resumidos.

Sostiene Kelsen aquí también, que la unidad metodológica del derecho presupone el primado del derecho internacional sobre los órdenes jurídicos nacionales, pero además, que dicha unidad a la vez se muestra como «una idea eminentemente ética [sittlich] y uno de los pocos realmente valiosos e indiscutidos elementos constitutivos de la conciencia cultural moderna.» ${ }^{49}$

Kelsen remite este ideal ético explícitamente a Christian Wolff, quien lo formula por primera vez como el ideal de una «civitas maxima», es decir,

\footnotetext{
${ }^{47}$ Kelsen, H., Reine Rechtslehre, op. cit., p. 143.

${ }^{48}$ Kelsen, H., Das Problem der Souveranität.... op. cit.

${ }^{49}$ Kelsen, H., Das Problem der Souveranität... op. cit., p. 204.
} 
un Estado mundial. A diferencia de Wolff, sin embargo, Kelsen no postula este ideal ético en cuanto tal, sino que intenta demostrar que el mismo es una condición de posibilidad del conocimiento jurídico. El teórico mantiene así su neutralidad frente a dicho ideal, en cuanto no hace sino constatar su carácter transcendental. Dicho de otra manera, Kelsen no formula el ideal en modo prescriptivo, sino que lo utiliza como herramienta metodológica, más precisamente como categoría transcendental. Como se vio más arriba, se sigue aquí a la letra el programa metodológico planteado por Hermann Cohen.

Siendo el primado del derecho internacional una condición de posibilidad del conocimiento jurídico, sólo puede considerarse al derecho como algo dado cuando se adopta este punto de vista objetivista-universalista. El punto de vista subjetivista, en cambio, sólo puede ser el «punto de vista de la fuerza», dado que, desde el mismo, el derecho, en última instancia, no es posible: «La tendencia subjetivista que subyace a la teoría del primado del orden jurídico estatal conduce desde su posición fundamental a la negación del derecho internacional y desde aquí a la negación de la idea jurídica -por lo menos en esta esfera- y a la afirmación del puro punto de vista de la fuerza. Así como el mismo pensamiento seguido consecuentemente en la esfera del derecho estatal lleva, como primado del individuo, a la negación del derecho en general, y a la proclamación de la idea de la fuerza en toda la línea.» ${ }^{50}$

Con esto llegamos a la conclusión de la argumentación de Kelsen. El ideal de la «civitas maxima» representa en síntesis, en cuanto norma fundamental supranacional, la categoría transcendental que hace posible tanto el conocimiento del derecho en cuanto tal como su propia realidad. Sin la presuposición de una unidad universal de todo derecho es el fenómeno jurídico, para Kelsen, tan inexplicable como imposible.

La norma fundamental tiene por lo tanto que valer como la fuente de la unidad de todos los órdenes jurídicos nacionales. Con esto ha mostrado Kelsen de forma bastante convincente, a mi modo de ver, que una presuposición de contenido ético puede tener un rol metodológico en la teoría del derecho. Sin embargo, entiendo que la Teoría Pura no deja por esto de ser una teoría positiva del derecho: el principio ético se pone a prueba sólo como condición de posibilidad del factum del derecho. Este positivismo no implica una renuncia a principios de la ética como fundamentos metodológicos. A mi juicio, lo que Kelsen entendía por positivismo, en oposición al derecho natural, es que el jurista no formula y fundamenta principios éticos que hayan de servir de criterio a principios jurídicos, sino que se limita a

${ }^{50}$ Kelsen, H., Das Problem der Souveranität.... op. cit., p. 317. 
constatar la eventual presencia de aquellos como condición de posibilidad del fenómeno a estudiar.

Un positivismo con estas características podría denominarse tanto positivismo transcendentalista como positivismo neokantiano. Las formas transcendentales de argumentación lo diferencian claramente del positivismo lógico, pero mucho más aún las presuposiciones valorativas a las que hemos hecho referencia. Que éstas son esenciales en el concepto del método desarrollado por Kelsen es afirmado por éste de manera enfática al final de la argumentación expuesta hasta ahora: «Tanto como para una concepción objetivista de la vida el concepto ético del hombre es la humanidad, es para una teoría jurídica objetivista el concepto del derecho idéntico con el del derecho internacional, y precisamente por esto, a la vez, un concepto ético..» ${ }^{51}$

\section{Conclusión}

La argumentación de Kelsen que acabo de reproducir aquí se encuentra delimitada en un período de su obra, esto es, no antes de 1928 y no después de 1934, fechas de publicación de las únicas dos obras que he considerado. En este marco son explícitas las referencias a un punto de vista universalista como soporte metodológico de la Teoría Pura del Derecho. La propia calificación de este punto de vista como un punto de vista ético es también explícitamente sostenida por Kelsen. He intentado mostrar que, a través de ciertos paralelos con la Ética de Cohen, puede entenderse el rol metodológico que una ética universalista adopta en el Teoría Pura del Derecho. Entiendo que esta época del desarrollo de las ideas de Kelsen afecta al resto de su obra, de la que no puede tampoco afirmarse sin más la neutralidad valorativa pretendida muchas veces por su autor. Dado que este último problema afecta, sin embargo, a la periodización de la obra de Kelsen y, por tanto, a una cantidad de sus obras que no podría tratar aquí, voy a dejar abierto este aspecto de la cuestión.

${ }^{51}$ Kelsen, H., Das Problem der Souveranität... op. cit., p. 319.

\section{DOXA 21-II (1998)}

